\title{
HEALTH PROMOTION
}

\section{Sick planet, sick patients}

\section{The health impacts of climate change}

Charlotte Hunter (Meds 2015)

Faculty Reviewers: Dr. John Howard, MD, FRCPC (Departments of Medicine and Paediatrics)

In 2007, Dr. Margaret Chan, the Director General of the World Health Organization (WHO), referred to climate change as "the defining issue for public health during this century."1 In spite of this pronouncement, many members of the public, and of the medical community, do not fully appreciate the link between anthropogenic greenhouse gas emissions, rising average global surface temperatures, and human health. In a series of in-depth interviews with 22 residents of Southern Ontario, researchers found that $77 \%$ of interviewees believed that climate change would have health impacts. ${ }^{2}$ However, the study participants were generally unable to provide details about the specific health effects of climate change or to put these effects in the context of their own community and their own health.

Although the developing world is much more vulnerable to the expected health impacts of climate change, ${ }^{3}$ this article will examine the health effects anticipated in Canada and other industrialized nations. It will also demonstrate that the responsibility for addressing these health impacts lies with primary care providers, emergency department physicians, and other medical specialists not just with public health officials. Finally, it will describe these impacts in the context of how they will affect the most vulnerable members of Canadian society.

Perhaps the most obvious health impact of climate change relates to the increased frequency and intensity of heat waves. We have already begun to experience this effect of climate change: in Toronto, the number of days above $30^{\circ} \mathrm{C}$ each year nearly doubled during the period of 1995-2005 compared to the period of 19611990. ${ }^{4}$ Due to the urban heat island effect, which is when the abundance of concrete and asphalt in cities traps more heat compared to rural areas, heat-related mortality is expected to be greatest in urban areas. ${ }^{5,6}$ Climate change models have projected a fourfold increase in the number of extreme heat warnings in Toronto by the 2080s, which could lead to a tripling of heat-related deaths. ${ }^{4}$ Risk factors for heat-related mortality include: extremes of age; living alone and being socially isolated; pre-existing medical conditions like cardiovascular, cerebrovascular, or pulmonary disease; psychiatric illnesses; not having air conditioning; being homeless; and working long hours outdoors. ${ }^{5-7}$

Climate change is also expected to lead to an increase of air pollution-related morbidity and mortality. Higher temperatures lead to increased concentrations of ground-level ozone, which can lead to exacerbations of COPD, asthma, and cardiac disease. ${ }^{6,7}$ There is also concern that climate change will increase pollen production and the duration of the pollen season. These changes are expected to cause increased morbidity associated with allergic rhinitis and asthma, especially among children., ${ }^{5,8}$

The prevalence of extreme weather events, including storms and floods, is expected to increase with climate change. In fact, it has been estimated that there was a $24 \%$ increase in the frequency of extreme precipitation events in the United States between 1948 and 2008. ${ }^{9}$ Health effects of extreme weather events can include: drownings; injuries; infectious disease outbreaks from contaminated water supplies; and mental illnesses like anxiety and depression. ${ }^{5-8,10}$ A longitudinal study of individuals affected by Hurricane Andrew, which occurred in the Southern United States in 1992, found that $20-30 \%$ of adults in the area met criteria for PTSD at 6 months and at 2 years after the event. ${ }^{6,10}$

Another major health impact of climate change will be the morbidity and mortality associated with changing infectious disease patterns. There has been an increase in the incidence of West Nile Virus infections in humans, from 62 cases in the United States when the virus was introduced to North America in 1999, to 1,338 cases in 2008. ${ }^{6}$ This trend is expected to continue as climate change leads to an earlier onset of spring and an extended amplification cycle for the virus. In general, warmer temperatures, increased precipitation, and elevated humidity are associated with an increased incidence of West Nile Virus. ${ }^{8}$ Similarly, climate change is expected to alter the geographic range of Lyme disease and other tick-borne diseases, with warmer temperatures allowing for a northward migration of the tick vector. ${ }^{7,8}$ Finally, climate change may lead to increased transmission of water- and food-borne illnesses (such as Cryptosporidium and Salmonella, respectively), as warmer temperatures allow for pathogen survival and increased precipitation facilitates contamination of drinking water supplies. ${ }^{7,8,11}$

As demonstrated above, the health impacts of climate change are not merely theoretical, nor are they restricted to the developing world. They include tangible health problems that fall within the scope of practice of Canadian physicians. Medical students, residents, and physicians should familiarize themselves with the changing epidemiology of diseases associated with climate change and be prepared to address these health issues in a clinical setting. In a recent commentary for Canadian Family Physician, Dr. Alan Abelsohn and others outlined the clinical treatment and prevention of several health problems associated with climate change. ${ }^{7}$ Some examples include: preventively counseling individuals at high risk of heat exhaustion; treating injuries and PTSD after extreme weather events; counseling patients with COPD, asthma, or cardiac disease to reduce their exposure to air pollutants; diagnosing and treating Lyme disease with doxycycline; and participating in the surveillance of water- and food-borne diseases.

Another important reason to be concerned about the health impacts of climate change relates to the equity dimension of the problem: climate change will disproportionately affect the most vulnerable members of society. Children will be at an increased risk for morbidity associated with heat waves, air pollution, and gastroenteri- 


\section{HEALTH PROMOTION}

tis due to water- and food-borne pathogens. ${ }^{8}$ Elderly individuals will be highly susceptible to heat-related mortality and many of the other health impacts mentioned above due to their existing burden of chronic disease. ${ }^{7}$ Homeless individuals will be highly susceptible to heat exhaustion, the effects of extreme weather events, air pollution, and mosquito-borne diseases like West Nile Virus, due to their lack of shelter and increased amount of time spent outdoors. ${ }^{6}$

Canada's Aboriginal population will perhaps face the greatest burden of illness associated with climate change. The traditional diet of some Aboriginal communities could be compromised as the changing climate alters the populations of animals depended upon for subsistence hunting. ${ }^{11}$ The increased survival of water-borne pathogens could contaminate water supplies in more marginal locations, while food-borne pathogens could threaten traditional diets that include raw meat. ${ }^{11,12}$ In more remote communities, coastal erosion due to rising sea levels, extreme weather events, and changing ice distribution could lead to community displacement and psychological harm. ${ }^{11,12}$ In addition, all of the health problems discussed previously with respect to the general population are likely to be exacerbated by the poverty, lack of access to health services, food insecurity, overcrowded housing, and other social inequalities already disproportionally affecting Aboriginal communities. ${ }^{11}$

It is evident that anthropogenic climate change will have adverse health impacts on our patients and communities. It will also worsen existing health inequalities in our society. As members of the medical profession, we have a duty to address these health problems when they arise in our clinical practices, while supporting public health programs that aim to prevent climate-related illness from occurring in the first place.

Scientists and policymakers addressing climate change have often called for a two-pronged strategy that includes both mitigation and adaptation. Much of what has been discussed previously would be considered adaptation, as it involves reducing our vulnerability to the effects of climate change. While this may seem like the natural sphere of action for health care professionals, I would dare to argue that we have just as much of a duty to participate in climate change mitigation. This would involve being vocal advocates for carbon dioxide emission reductions, calling for investment in renewable energy infrastructure, and reducing the energy consumption of our clinics and hospitals. Given the profound health impacts of climate change, these actions should be considered primary prevention - and that's just good medical practice.

\section{REFERENCES}

1. Chan M. World Health Organization. Climate change and health: preparing for unprecedented challenges. Geneva: World Health Organization; 2007. Available from: www.who.int/dg/ speeches/2007/20071211_maryland/en/index.html.

2. Cardwell FS, Elliott SJ. Making the links: do we connect climate change with health? A qualitative case study from Canada. BMC Public Health. 2013;13(208):1-12.

3. Costello A, Abbas M, Allen A, Ball S, Bell S, Bellamy R, et al. Managing the health effects of climate change. Lancet. 2009;373:1693-733.

4. Cheng CS, Campbell M, Li Q, et al. Differential and Combined
Impacts of Winter and Summer Weather and Air Pollution Due to Global Warming on Human Mortality in South Central Canada. Technical Report submitted to Health Policy Research Program. Health Canada, 2005. Available from: http://www. toronto.ca/health/hphe/weather_air_pollution_research.htm.

5. Haines A, Patz JA. Health effects of climate change. JAMA. 2004;291(1):99-103.

6. Ramin B, Svoboda T. Health of the homeless and climate change. Journal of Urban Health. 2009;86(4):654-64.

7. Abelsohn A, Rachlis V, Vakil C. Climate change: should family physicians and family medicine organizations pay attention? Can Fam Physician. 2013;59:462-6.

8. Ebi KL, Paulson JA. Climate change and child health in the United States. Curr Probl Pediatr Adolesc Health Care. 2010;40:2-18.

9. Madsen T, Figdor E. When it rains it pours: global warming and the rising frequency of extreme precipitation in the United States. Washington DC: Environment America Research \& Policy Center; 2007.

10. Greenough G, McGeehin M, Bernard SM, Trtanj J, Riad J, Engelberg $\mathrm{D}$. The potential impacts of climate variability and change on health impacts of extreme weather events in the United States. Environ Health Perspect. 2001;109(Suppl 2):191-198.

11. Ford JD, Berrang-Ford L, King M, Furgal C. Vulnerability of Aboriginal health systems in Canada to climate change. Global Environmental Change. 2010;20:668-80.

12. Ford JD. Indigenous health and climate change. Am J Public Health. 2012;102:1260-66. 